\title{
NOVES DADES SOBRE LES RELACIONS ENTRE EL SOLDÀ DEL CAIRE AL-NĀSIR MUHAMMAD IBN SAYF AL-DİN QALAWWN I EL REI JAUME II
}

\author{
Mercè VILADRICH \\ Universitat de Barcelona
}

Al-Nāșir Muhammad ibn Sayt al-dīn Qalāwūn accedeix al poder suprem de la cort mameluca en tres períodes: entre el 692/1293 i el 693/1294, quan encara no tenia 10 anys; després, entre el 698/1299 i el 708/1309; i, la tercera vegada, per establir una de les autocràcies més fortes que han caracteritzat el poder polític mameluc, i més persistents, ja que va prollongar-se des del $709 / 1310$ fins al $741 / 1341$.

1 Sobre els esdeveniments que caracteritzaren la seva època, vegeu IRWIN, R., The Middle East in the middle ages. The early Mamluk Sultanate 1250-1382. Londres, Sidney: Croom Helm, 1986, amb nombroses referències bibliogràfiques sobre els aspectes més variats de la història del soldanat mameluc. Vegeu també HOLT, P.M., «Mamlūks». A: Encyclopédie de l'Islam, El , vol. VI, Leiden-París, 1987, pp. 305-315. Aquest autor ha publicat recentment un estudi sobre qüestions diplomàtiques immediatament anteriors a l'època que estudiem: HOLT, P.M., Early Mam/uk Diplomacy (1260-1290). Treatises of Baybars and Qalāwūn with Christian Rules. Leiden; E.J. Brill, 1995. Sobre el tercer soldanat d'al-Nāșir Muhammad vegeu LEVANONI, A., A Turning point in Mam/uk History. The Third Reign of alNaşir Muhammad Ibn Qalāwūn (1310-1341). Leiden: E.J. Brill, 1995.

Pel que fa a les fonts historiogràfiques àrabs, suggerim consultar les obres següents:

LITTLE, D.P., History and Historiography of the Mam/uks. Londres: Variorum Reprints, 1986.

L'historiador egipci, Taqī al-Dīn Ahmad ibn 'Alī al-MaqrTZT. Aquest autor, nascut al Caire el 766/ 1364 i mort el 845/1442, jurista de la cancelleria del soldanat i mestre de tradicions, va redactar, després d'una estada de cinc anys a la Meca, una descripció d'Egipte (Hițțt) i una Crònica de les dinasties aiúbida i mameluca (Kitāb al-sulak) que cobreix el període comprès entre el 1166 i el 1441. Existeix una edició deguda a ZIYADA, M.M. et al., Kitäb al-sulūk lï-macrifat duwal al-mulūk. 6 vol. El Caire: 1956. QUATREMĖRE, E. va publicar una traducció a partir del ms. de París (BN, Arabe 1727): Histoire des sultans mamlouks de l'Égypte. 2 vol. París: 1845. 
El procés diplomàtic entre el soldà al-Nāṣir Muḥammad i Jaume II va ser força enrevessat. Malgrat la seva complexitat, a hores d'ara disposem d'estudis que han aconseguit aclarir els entrebancs de les trobades diplomàtiques i que ofereixen descripcions exhaustives i prou acurades d'aquests esdeveniments, establertes a partir de l'edició de la documentació llatina i catalana conservada, majoritàriament, a l'Arxiu de la Corona d'Aragó ${ }^{2}$. Ens plau, doncs, afegir a aquestes informacions un document àrab inèdit, $i$ que en part complementa les notícies conegudes fins ara.

L'Arxiu de la Corona d'Aragó guarda quatre cartes àrabs a través de les quals es van trametre les respostes del soldà Muḥammad ibn Sayf al-dīn Qalāwūn a les

BLOCHET, E., «Moufazzal ibn Abit-Fazail. Histoire des sultans mamluks». A: Patrologia Orientalis. Vol. 14, 1920; vol. 20, 1929.

Abū-l-Fidā'. Al-mubtaşar fi ahbār al-bašar. 4 vol. Istanbul: 1869-1870. Trad. parcial HOLT, P. M. The Memoirs of a Syrian Prince. Wiesbaden: 1983.

Ibn al-Ṣuqā̄T, Tă/T kitāb wafayāt al-açyān. SUBLET, J. (ed. i trad.). Damasc: 1974.

Ibn al-Dawādāri. Kanz al-durar wa-jāmic al-ghurar. Vol. VIII. HAARMANN, U. (ed.). El Caire/Freiburg: 1391/1979.

Al-Ğazari. La Chronique de Damas d'al-Jazari (années 689-698 H). Trad. SAUVAGET, J. París: 1949.

Ibn al-Furăt. Tarikh al-duwal wa'l-mulūk. Vol. VIII. ZURAYQ, Q.; IZZ AL-DIN, N. (ed.). EL Caire: 19391941.

Ibn al-Tağĭbirdì. Al-nujūm al-zähira fī mulük Mișr wa'l-Qāhira. Vol. 8. El Caire (sense data).

Anònim. A: Beiträge zur Geschichte der Mamluksultane. ZETTERSTEEN, K.V. (ed.). Leiden: 1929.

2 Vegeu MASIÀ DE ROS, A., La Corona de Aragón y los estados del norte de África. Política de Jaime II y Alfonso IV en Egipto, Ifriquia y Tremecén. Barcelona: Instituto Español de Estudios Mediterráneos, 1951. Amb relació al procés diplomàtic amb Egipte, l'obra publica un magnífic apèndix documental, amb textos cadbals per entendre les sis ambaixades de Jaume II al Caire, els anys 1303, $1305,1314,1318,1322$ i 1327. A més a més, dedica una atenció especial als fets ocorreguts a Alexandria el 1305, quan es produi l'enfrontament dels ambaixadors Eimeric i Fahr al-Dĩn. Vegeu pp. 58-77 i apèndix. L'estudi de MASIÀ DE ROS permet esbrinar la via accidentada per la qual la llista de regals que editem va arribar al seu destí final a Barcelona.

En data més recent GIUNTA, F. va reproduir la narració dels fets establerta per MASIÀ a Aragonesi e catalani nel Mediterraneo. II: La presenza catalana nel levante dalle origini a Giacomo II. Palerm: U. Manfredi Editore, 1959. Trad. cast.: Aragoneses y catalanes en el Mediterráneo. Barcelona: Ariel, 1989. Vegeu pp. 86-122. Ambdós autors donen nombroses referències bibliogràfiques.

Altres estudiosos havien fet referència al procés diplomàtic entre Jaume II i Muhammad ibn Qalāwūn. Encara que la descripció dels fets no hi és completa, cal tenir en compte l'obra de GOLUBOVICH, P.G., Biblioteca Bio-Bibliografica della Terra Santa e dell'Oriente Francescano. 3 vol. Florència: 19061913. GOLUBOVICH edita, acompanyades de versió italiana, les cartes catalanes de les ambaixades del juny del 1303 , setembre de 1305,1318 , agost del 1327, i resumeix el contingut de les ambaixades del 1314 i el 1322. Vegeu vol. 3, pp. 73-85, 185-87, 232-236 i 309-317.

D'altra banda, ANTONI DE CAPMANY va traduir al castellà la carta d'una ambaixada catalana al soldà d'Egipte Muammad, datada a Lleida el 1314. Vegeu CAPMANY, A. de, Antiguos tratados de paces y alianzas entre algunos reyes de Aragón y dirigentes principales infieles de Asia y África, desde el siglo XIII hasta el XV. Madrid: 1786. Reed. facs. València: 1974, pp. 32-35. CAPMANY esmenta un registre de l'Arxiu Reial Jacobí II, titulat Legationum Jacobii II, ab anno 1318 ad 1327, fol. 138, on consta l'ambaixada al Caire, de l'any 1322, en què s'enviaren també alguns regals. Vegeu pp. 34-35. 
sol.licituds del rei Jaume II, documents en llengua àrab que corresponen a ambaixades egípcies dels anys 703/1304, 705/1306, 714/1315 i 723/1323, i que també han estat editades ${ }^{3}$.

A la segona carta, que ha estat publicada i traduïda al castellà per ALARCÓN i GARCÍA DE LINARES - que tracta de l'arribada a Egipte de l'ambaixador de sa majestat, Aul Eimeric ${ }^{4}$, i de les actuacions que el soldà proposa dur a terme en favor del rei cristià-, s'informa de la tramesa d'uns regals que el soldà del Caire envia al rei a través del príncep Fahr al-Dĩn i que, segons el contingut de la missiva, es detallen de forma específica en una llista a part. La carta i l'enviament de regals són resposta a l'ambaixada de Jaume II del 1305, encapçalada per Eimeric, en un segon viatge d'aquest a Egipte ${ }^{5}$. ALARCÓN i GARCÍA DE LINARES van editar i traduir el document principal $^{6}$, datat l'1 de šacbān de l'any 705/26 de febrer de 1306. Trobaren a faltar, però, la llista dels presents del soldà al rei Jaume, que creiem poder identificar entre els papers de la caixa IV dels documents àrabs de l'Arxiu de la Corona d'Aragó. EI document al que fem referència (avui a la caixa IV de documents àrabs, núm. 163) ${ }^{7}$

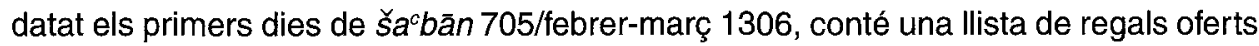
a Jaume II per part del soldà mameluc Al-Nāșir Muḥammad ibn Sayf al-dīn Qalāwūn, el segon dels fills de Qalāwūn que van ocupar el carreg de soldà. Mentre preparem l'edició del text àrab del document, la seva traducció i l'estudi del significat dels termes específics que designen els objectes de la llista, donem una descripció del document i del seu contingut.

\section{DESCRIPCIÓ}

Es tracta de tres fulls de paper enganxats, d'una amplada uniforme de $14 \mathrm{~cm}$ i de llargades distintes $(23,41$ i $20 \mathrm{~cm})$. El paper és fi, de color groguenc, tinta negra i

3 Les cartes han estat editades i traduïdes al castellà per ALARCÓN, M.A. i GARCÍA DE LINARES, R., Los documentos árabes diplomáticos del Archivo de la Corona de Aragón. Madrid: 1940. Vegeu pp. 350-368. La carta de l'any 1315 conté una llista de regals. A més a més, ALARCÓN i GARCíA DE LINARES editen altres cartes d'AI-Nāșir Muhammad, dues adreçades a l'infant Alfons de Castella (699/1300), una amb llista de regals; vegeu pp. 344-354. Unes altres dues missives són adreçades a Alfons IV d'Aragó (728/1328); vegeu pp. 368-371. Vegeu també HOLT, P.M., “Al-Nāșir Muhammad's letter to a Spanish ruler in 699/1300". A: Al-Masāq. 3, 1990, pp. 23-29.

4 Aul Eimeric era un ciutadà noble de Barcelona, amic personal del rei. Havia anat a Egipte anteriorment, encapçalant l'ambaixada del 1303. CAPMANY esmenta altres membres de la seva família, amb el cognom Dusay, que van ocupar càrrecs importants com a representants de la ciutat de BarceIona, a CAPMANY, A. de, Memorias históricas sobre la Marina, Comercio y Artes de la antigua ciudad de Barcelona. 3 vol. Barcelona: Cambra Oficial de Comerç i Navegació, 1961-1963. Vegeu vol. 2, pp. 69,70 i 89.

5 El document català enviat per Jaume II a al-Nâșir Muḥammad ha estat editat per MASIÀ DE ROS, núm. 28, pp. 292-293. Recordem que la resposta a aquest document és la segona carta editada per ALARCÓN i GARCÍA DE LINARES, on s'esmenta l'ambaixador barceloní amb el nom d'Aul Eimeric.

6 Pp. 355 i seg. Correspon al rotllo àrab núm. IV de l'Arxiu de la Corona d'Aragó.

7 Signatura antiga de l'Arxiu, núm. 19; Inventari Ribera, núm. 154; Inventari Vernet, núm. 163. 
cal-ligrafia oriental. Hi ha escrites algunes vocals i signes auxiliars. L'estat de conservació és bo i s'han enganxat unes bandes de paper al dors per protegir el diploma. És evident que es tracta d'un escrit independent del rotllo de paper que conté la carta, encara que els estils cal.ligràfics d'ambdós instruments són prou semblants i fàcilment identificables com a obres de la cancelleria mameluca.

\section{ESTUDI}

Pel que fa als regals, la tramesa consta, en primer lloc, de 20 peces de teixit.

El costum de regalar vestimenta a les persones estimades o respectades és molt antic al Pròxim Orient, encara que al-Maqrīzī, l'historiador egipci gairebé coetani dels fets que descrivim, atribueixi al califa Hārūn al-Rašĩd l'inici d'aquesta pràctica. DOZY crida l'atenció sobre l'honor que representa, per a qualsevol súbdit, rebre un regal d'indumentària del seu senyor. Fins $i$ tot, hi ha un terme genèric clàssic per designarlo, hika -tašrîf en època més moderna-, que significa «roba honorífica»8${ }^{8}$.

Entre els teixits regalats a Jaume II creiem que, des del punt de vista terminològic, crida especialment l'atenció la peça designada amb la paraula kanğğăā, d'origen xinès i introduïda a l'àrab a través del persa. Cal recordar que, entre d'altres, aquesta peça de roba duu țirāz, és a dir, els brodats propis d'un teixit destinat a vestir un rei ${ }^{9}$. D'altra banda, s'han conservat fins els nostres dies diverses peces de roba amb el țirāz del soldà Nāşir al-Dunyā wa'l-Dĩn Muḥammad ibn Qalāwūn, una de les quals és de fabricació xinesa ${ }^{10}$.

L'indument masculí i femení cairota en temps dels mamelucs, destaca per la seva complexitat i per l'evolució soferta des dels temps del Profeta, així com per l'ús de sedes estampades i vistoses en el vestir. Aquestes teles s'han fabricat, al llarg de tota l'edat mitjana, a les localitats artesanals egípcies, com ara Alexandria, Ajmim, Antinoa, al-'Aẓm, Banšãa, Damietta, Dabīq, Dumaira, Erment, al-Farama, Tinnīs i Tuna, conegudes per la producció de teles fines, robes de seda i de lli, estampades amb fil d'or, amb representacions florals o bé amb escenes de cacera, festes, concerts, danses, lluites i combats ${ }^{11}$.

8 DOZY assenyala que el regal de Hārūn al-Rašĩd anava destinat a Yaşyā el Barmekida. Sobre la tradició dels regals de roba, vegeu DOZY, R., Dictionnaire détaillédes noms de vêtements chez les arabes. Amsterdam: 1845 , p. 14 i nota 4.

9 "Ibn Khaldūn is very well informed about the institution of the tirāz; according to him, the majesty of the ruler found expression in his name or the royal badge ('alāma) being put in the border (țirāz) of the materials, which were used for his robes of silk or brocade, and the inscription was worked into the web of the material with gold thread or bright coloured yarn, wich stood out against the background of the material. The royal robes were thus distinguished to mark out the royal wearer, or him who received the garment from the ruler as a mark of special favour, to show him honour or appoint him to one of the higher offices in the kingdom». Vegeu «Tirāz». A: El, vol. VIII. p. 785.

10 Vegeu «Tirāaz». A: El, p. 786.

11 Sobre la producció tèxtil a Egipte i el Pròxim Orient, cal remetre a la consulta dels clàssics i a la bibliografia que esmenten sobre arts manuals i economia domèstica a l'edat mitjana. Vegeu:

MIGEON, G., Manuel d'art musulman, 2 vol. París: Auguste Picard, 1927. Vegeu vol. 2. Arts plastiques 
A vegades els historiadors àrabs clàssics descriuen escenes de donacions de regals, de roba i d'altres objectes com ara punyals, armes o cavalls. La llista de regals d'alNāṣir Muaḥmmad a Jaume II es acompleta amb la fusta de incens, uns arcs de mà ${ }^{12}$, una pomada en un vas de vidre $i$, tal vegada, un xiulet. És a bastament conegut l'interès de Jaume II i de la seva família més propera per les manifestacions externes de luxe, a través del vestir i de l'ús d'objectes personals opulents, que eren inventariats amb certa periodicitat a la cort catalana ${ }^{13}$. Entre els regals arribats del Caire $i$ els objectes valuosos de la cambra reial hi ha certes coincidències, com ara algunes peces de roba, les botzines o els xiulets, les ampolletes de bàlsam i tota mena d'armes, encara que res no podem afirmar sobre la destinació final dels regals del soldà ${ }^{14}$. L'obsequi d'atuells valuosos de tota mena era una pràctica habitual del rei Jaume II envers els membres de la seva família i els seus servidors més fidels ${ }^{15}$.

Al document objecte d'estudi no s'esmenten ni el nom del soldà ni el nom del rei, fet que ben segur ha entorpit la identificació com a llista de regals que manca a la carta del $1306^{16}$. Efectivament, la data que conté correspon a l'ambaixada de la primeria et industriels, pp. 279-348. Vegeu també HEYD, W., Histoire du commercedu levant au moyen-âge. Supplément: Articles d'échange entre l'Orient et l'Occident: «Soie», pp. 670-674; “Fils d'or et d'argent», pp. 677-678; «Tissus", pp. 693-701.

12 Alguns destinats a la caçera i d'altres d'aplicació bèlḤlica. Cal recordar que les armes com ara arcs, artinets, fonèvols, gates, gosses, etc. són armes de soldat i no pas de l'armament personal cavalleresc.

13 Vegeu —com a testimoniatge de l'opulència de la cort catalana d'aleshores- les obres que indiquem tot seguit: MARTORELL I TRABAL, F., «Inventari dels béns de la Cambra reyal en temps de Jaume II". A: Anuari de I'Institut d'Estudis Catalans. 1911-1912, pp. 553-567; GONZÁLEZ HURTEBISE, E., Libros de la Tesorería de la Casa Real de Aragón. Barcelona: 1911; i MARTÍNEZ FERRANDO, J., «Datos sobre el vestuario de Jaime II de Aragón». A: Anales y Boletín de los Museos de Arte de Barcelona. 1945. pp. 5-17.

14 Vegeu MASIÀ DE ROS, p. 107. No hem trobat referència a l'entrada dels regals del soldà d'Egipte a la cambra reial de Jaume II. Això no obstant, entre els objectes d'aquesta se'n troben de procedència egípcia i tunisiana, com ara uns bacins pochs de coure de obre d'Alexandria, un traveser ab cuberta de bort d'Alexandia, una pessa de bort d'Alexandria de seda llistada ab camp vermell, iii draps de seda e ii borts d'Alexandria, vii barrats de Tuniç, una pessa de drap appelat bort d'Alexandria a semblant de manil... Vegeu l'inventari del 1323 dels objectes de Jaume II publicat per MARTORELL, F., «Inventari dels béns de la Cambra reyal...". pp. 553-567.

15 Vegeu el diplomatari dels documents d'entrada i sortida d'objectes preciosos de la cambra reial, publicat per MARTÍNEZ FERRANDO, J.E., "La Cámara Real en el reinado de Jaime II (12911327). Relación de entradas y salidas de objetos artísticos". A: Anales y Boletín de los Museos de Arte de Barcelona, XI, 1953-1954. En un altre treball, aquest autor assenyala: «De esta clase de objetos preciosos de ornato de la persona.. hizo don Jaime frecuentes repartos, entre sus hijos y la reina, asi como también a otros personajes predilectos. Nos referimos a los cinturones y correas forrados de seda en los que iban "cabadas" perlas y piedras preciosas, carners (zurrones), marsupias (bolsos), orcleria (¿pendientes?), anillos, bocinas, paternosters, espadas y cuchillos...". Vegeu Datos sobre el vestuario de Jaime I/ de Aragón, pp. 13-14. Indica també que el registre de Cancelleria Reial 279 , fol. $1 \mathrm{v}, 44$ i 247 conté la descripció de nombroses armes.

16 D'altra banda, no deixa de ser contradictori que un rei immers en un procés conqueridor contra els musulmans de la península lbèrica rebi un tractament tan afalagador. En qualsevol cas és ben conegut l'interès del soldanat mameluc de ser proveït pels mercaders occidentals. 
de šacbăn del 705/febrer-març del 1306, moment en què Eimeric es disposava a tornar a casa.

Eimeric, però, no va portar els regals a Barcelona i tampoc no va lliurar personalment cap dels dos documents esmentats, sinó que va refugiar-se a Sicíia, irritat pels fets d'Alexandria i pel fracàs envers els objectius del seu rei ${ }^{17}$. D'acord amb la descripció de l'episodi que dona MASIÀ DE ROS, Jaume Il, quan tingué notícia d'aquests incidents, i de la retenció dels captius cristians, va fer certes indagacions a l'entorn del que havia succeït. Eimeric va donar, a través de Pere de Munels, canceller i conseller del rei, una versió pròpia dels fets - d'interès cabdal a l'hora d'esbrinar que se'n va fer dels regals i de la llista que editem-, disculpa en la qual Eimeric assenyalava els esforços personals que havia dedicat a la missió diplomàtica i la inversió generosa en el repartiment de presents als ministres del soldà, entre els quals acusa directament Fahr al-Din per la seva cobdícia.

MASIÀ DE ROS ${ }^{18}$ edita la carta d'Eimeric a Pere de Munels, en la qual l'ambaixador fa saber al rei que li arribaran, juntament amb els documents escrits i a través dels seus companys de viatge, alguns objectes que li envia el soldà del Caire. La valoració que en fa Eimeric és més aviat pobra:

«La pau senyer que es en sarrahinesch e encara la carta quel Soudan tramet al senyor Rey, ab alcunes altres coses que son asats poques, li tramet per los dits frares Lop de Liuranes e per Frare G. de Villalba e per en Pere Duzay frare meu; e els senyor li diran largament les falcies ni les desleyaltats $a b$ que nos son anatz ni con falsament man robat tot quan avia; ni tot quan jo avia pogut trobar a manlevar; e si mes nagues trobat; mes $n$ agueren ahut..." (MASIÀ DE ROS, pp. 297-298).

Així, doncs, varen ser els dos frares $i$, en Pere, el germà d'Eimeric, els qui van arribar finalment a Barcelona, amb la carta, els regals i la llista.

Juntament amb la petició de disculpa enviada des de Sicília, Eimeric va suggerir al rei Jaume II d'enviar quatre o cinc navilis per interrompre el trànsit comercial dels ports mediterranis amb Alexandria:

17 Després d'haver obtingut algunes concessions del soldà amb motiu de la segona ambaixada del 1305 (com ara l'autorització als cristians a practicar la litúrgia lliurement en terres orientals, la fi de les persecucions, la lliure circulació de pelegrins i la llibertat d'alguns presoners), Eimeric havia de tornar a Barcelona amb l'emir Faḩr al-Dīn cUțmān i un grup de captius catalans alliberats. Poc abans de salpar d'Alexandria, alguns d'aquests captius van ser retinguts i tornats a empresonar. Eimeric, irritat a causa dels enganys i la dilació del procés, va salpar abandonant immediatament l'ambaixador Fahr al-Dīn en una platja alexandrina i va fugir d'Egipte en direcció a Sicília amb els presoners alliberats, els regals del soldà i els documents que aquest havia entregat a Fahr al-Din (el text d'un tractat de pau que Eimeric considerava humiliant per al rei Jaume, la carta diplomàtica i la llista d'objectes que ara publiquem). Les pàgines 100-105 de l'obra de MASIÀ DE ROS són cabdals per conèixer les peripècies de tot aquest tràngol diplomàtic (vegeu supra nota 3 ).

18 Vegeu MASIÀ DE ROS, doc. núm. 31, pp. 296-97. 
«... cor es I dels pus grans mals que hom los puixa fer que hom destrenga que crestia noy vaj; per ço senyer cor tota la terra ha gran profit del anar dels crestians; $E$ que no porien viure sens ço que crestians lur porten" (MASIÀ DE ROS, p. 298).

La valoració d'Eimeric posa de manifest que el soldanat mameluc travessa una situació difícil al principi del segle XIV, crisi econòmica descrita pels historiadors contemporanis i perceptible també als ulls de l'ambaixador Eimeric ${ }^{19}$.

Sospitant la vàlua que informacions d'aquest caire podien tenir a l'hora de definir les estratègies bèl.liques i comercials catalanes al Pròxim Orient, destaquem el paper d'observador de la situació del soldanat egipci que juga l'ambaixador de Barcelona. Per la nostra banda, hem recuperat un text àrab de l'Arxiu de la Corona d'Aragó, que completa els editats fins ara, i que s'escau en el context del conflicte diplomàtic entre Jaume Il i el soldanat mameluc.

19 Vegeu les anàlisis d'ASTHOR, E., A Social and Economic History of the Near East in the Middle Ages. Londres: 1976; Studies on the Levantine Trade in the Middle Ages. Londres: Variorum Reprints, 1978; Levantine Trade in the Later Middle Ages. Princeton: 1983; i Technology, Industry and Trade. The Levant versus Europe, 1250-1500. Londres: Variorum Reprints, 1992. 